\title{
Diverging patterns of education premium and school attendance in France and the US: a Walrasian view
}

\author{
David de la Croix
}

FNRS, IRES and CORE, Univ. cath. Louvain
Frédéric Docquier

CADRE, Univ. Lille 2, and IZA Bonn

July 30, 2003

\begin{abstract}
We evaluate the effect of technology, demographics and policy on the differential evolution of the skill premium and on the rise in education investment in France and the USA. We use a computable general equilibrium model with overlapping generations of individuals, and endogenous education decisions. Human capital is made of two substitutable components, experience and education, both of them evolve endogenously over time. We calibrate this model on the post-war period and run counterfactual experiments to assess the effect of the different exogenous variables. French expansionary education policy boosted the supply of skills and kept the skill premium low. On the contrary, increasing education costs in the US contributed to increase wage differentials by reducing the supply of skills. The skill biased technical shock is key to understand rising school attendance and appears delayed in France.
\end{abstract}

Keywords: Human capital, Education, Experience, Skill premium. JEL Classification: J31, D58

\footnotetext{
${ }^{1}$ Acknowledgements: We thank the participants to the colloquium in the honor of Philippe Michel (Paris, 2002), to the Symposium on Forecasting Global Income Growth (Hawaai, 2003), to the IRES macro workshop (Louvain-la-Neuve, 2003), to seminars in Lille and IZA Bonn, and specially to Raouf Boucekkine, Patricia Crifo, Bart Hobijn, Sebnem Kalemni-Ozcan, Oliver Paddison and Henri Sneessens for helpful comments on an earlier draft. We thank Marie Janin for obtaining education price data from INSEE. David de la Croix acknowledges the financial support of the Belgian French speaking community (Grant ARC 99/04-235 "Growth and incentive design") and of the Belgian Federal Government (Grant PAI P5/10, "Equilibrium theory and optimization for public policy and industry regulation"). Contact address: David de la Croix, IRES, Place Montesquieu 3, B-1348 Louvain-la-Neuve, Belgium. delacroix@ires.ucl.ac.be.
} 


\section{Introduction}

During the last three decades, most industrialized countries have experienced a remarkable increase in the educational attainment of their labor force. The average skill level is expected to increase further in the coming years as younger (and more educated) cohorts progressively replace older (and less educated) ones. In spite of this, returns to skills have also increased substantially in countries such as the US, the UK and, to a lesser extent, Canada. By contrast, in most countries of continental Europe, the skill-premium has remained constant or has decreased as in France. This is illustrated in Figure 1 for the US and French cases. It represents estimates by Wasmer (2001a) of the skill premium for different levels of education. We clearly observe the contrast between France, where the skill premium actually declined, and the US. On the contrary, the qualitative pattern of the return to experience is similar in both countries: as reported in Figure 2, it peaked in the eighties, then declined in both countries. However, the magnitude of the changes is stronger in France.

The existing literature has explained the contrast between France and the US by referring to differences in labor market institutions: in face of a skill-biased technical progress affecting both countries, the US reacted by displaying a higher skill premium while France minimum wage legislation and/or unemployment insurance prevented unskilled workers' wages to fall (see Ljunqvist and Sargent (1998), Marimon and Zilibotti (1999)). Consequently, unemployment rates clearly increased in Europe (increased somewhat in Canada) and not in the US. Such a story is however not fully convincing. If differences in the flexibility of labor market institutions actually explain a diverging path of skill premium, we should observe diverging patterns of employment rates (employment - population ratio) as well. Indeed, facing a similar shock, responses of employment rates are expected to be stronger in low flexibility countries. Card, Kramarz, and Lemieux (1999) show that the evolution of employment rates across age and education groups in France, Canada and the US is almost identical. They conclude that a pure labor market rigidity cannot explain the diverging pattern of wage inequality and employment.

Building on the idea that the long-run path of wages is determined by demand and supply changes in the labor market, this paper provides an alternative (neo-classical) interpretation for the diverging path of wage inequality. Typically, we will argue that general equilibrium phenomena can explain returns to skills and wage inequality in 
Figure 1: Skill premium in France (left panel) and the US (right panel)
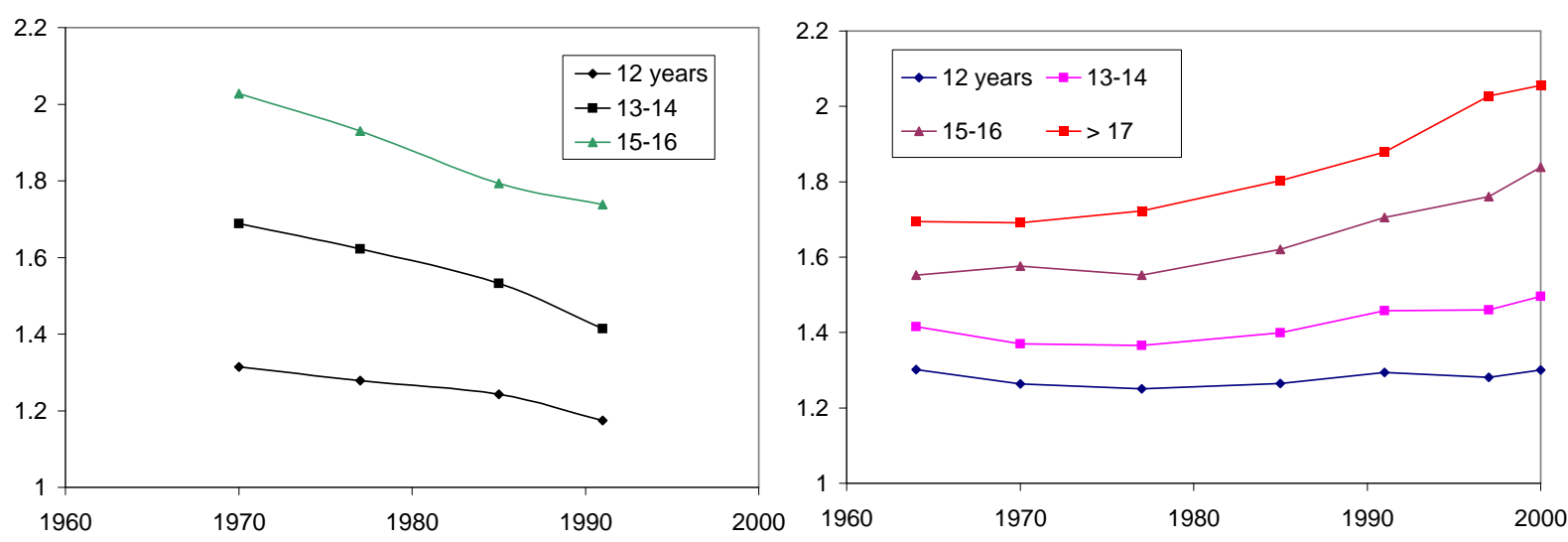

Note: the premium is calculated as the ratio of the wage associated to $x$ years of schooling over the wage associated to less than 12 years of schooling.

Figure 2: Experience premium (20 years)

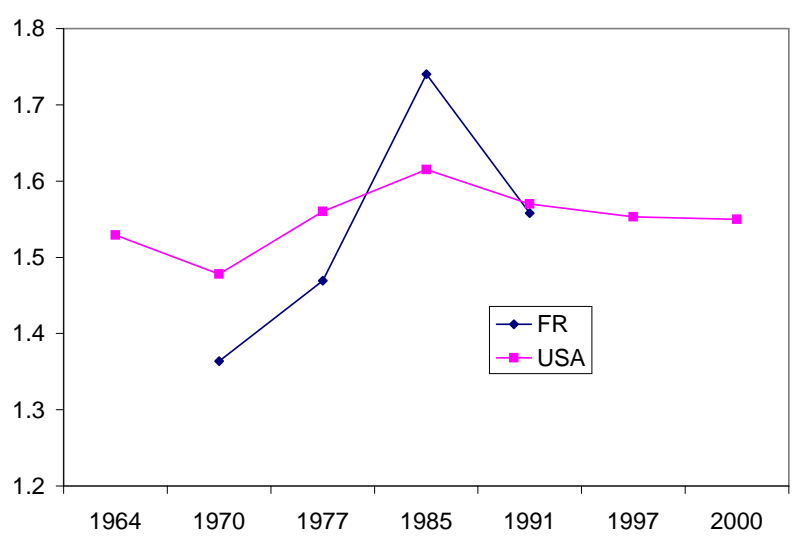

Note: the premium is calculated as the ratio of the wage associated to 20 years of experience over the wage associated to no experience. 
the last decades without relying on labor market rigidity features. We shall disentangle the effect of demographic variables, changes in participation rates, education policy and technical change.

Some stylized facts clearly illustrate the magnitude of supply shocks. Population data by age for 1960, 2000 and 2050 are presented in appendix A. The main difference between France and the US is for the period 2000-2050, where aging is much more pronounced in France. The share of individuals aged 65 and more rises from 18.9\% in 1960 to $23.3 \%$ in 2000 and $36.6 \%$ in 2050 in France; it rises from $16.7 \%$ in 1960 to $18.8 \%$ in 2000 and $30.2 \%$ in 2050 in the US. The importance of aging can affect current labor market outcome, through expectations; labor supply will indeed be more scarce in France than in the US, and future wages can thus be expected to be higher. Another significant difference between the US and France lies in the investment in education. Appendix B reports the share of time invested in education for the population aged 15 to 24 . Education was much higher in the US around 1960, but France caught-up and almost rejoined the US level in 2000. This trend dramatically increased the supply of skills in France, and may have reduced the skill premium. Magnac and Thesmar (2002) explain the rise between 1982 and 1993 by a change in the French education policy, which increased the chance for students to reach higher levels of education. Another difference between the US and France concerns the participation rate of old workers. Figure 11 shows the effective retirement age as computed by Blondal and Scarpetta (1997). The stronger drop in France should have reduced the incentive to accumulate skills since the productive time of education investment is shortened.

In this paper, we study the effect of these global trends on the labor market, and in particular on the returns to human capital, and on the investment in education. Following Becker (1964), human capital is built essentially through on-the-job-training and schooling; on-the-job-training reflects the idea that "many workers increase their productivity by learning new skills and perfecting old once while on the job". In the micro-econometric literature on wage formation (Mincer-type equation), both education and experience are shown to have a strong influence on individual earning. Accordingly, we define human capital as having two major and substitutable components, education and experience. Education and experience have never been distinguished in existing general equilibrium models with realistic demographics, which at most endogenize labor participation rates per age. The hypothesis of perfect substitution between young workers and old workers is a common assumption in that 
literature. An exception is the paper by Heckman, Lochner, and Taber (1998) who use a general equilibrium model with a sophisticated labor market. They calibrate their human capital production functions using econometric estimates of wage equations, however, they do not simulate their model with realistic population scenarios.

The model described in section 2 is distinct from the existing literature by three features: education and experience are two components of human capital, households optimally choose their investment in education, and households have access to perfect insurance markets to face lifetime uncertainty. We calibrate the model on the postwar period for France and the USA in section 3, using detailed demographic data, age profiles for taxes and transfers, and observations for educational attainment, retirement age and participation rates. Exogenous processes for technical progress and private costs of education are identified by letting the model match observed skill premia and investments in education. In section 4 we run counterfactual experiments and compute the endogenous path for skill premia and education when each exogenous variable is kept at its 1960 level. This gives us estimated marginal effects of technology, demographics and policy on the difference in the observed evolution of the skill premium in France and the USA. Three results arise. French expansionary education policy boosted the supply of skills and kept the skill premium low. On the contrary, increasing education costs in the US contributed to increased wage differentials by reducing the supply of skills. The skill biased technical shock is key to understand rising school attendance and appears delayed in France. Section 5 provides sensitivity analysis of some of our assumptions. Section 6 concludes.

\section{The model economy}

Our model depicts a closed economy with three agents: households, firms and the public sector. Individuals are homogenous ${ }^{1}$ within each generation and live a maximum of 8 periods of time (i.e. from age 15 to 95), each of them representing 10 years.

\footnotetext{
${ }^{1}$ It should be noted that our model is calibrated so as to match representative behavior of French and American residents, including natives and foreign-born. As Illustrated in Borjas (2001) for the US, the 1965 "Amendments to the Immigration and Nationality Act" has drastically changed the national origin mix and the relative skills of immigrants, increasing their difference with natives. Obviously, a model with heterogeneous agents as in Storesletten (2000) would allow to examine the relative contribution of immigration to rising wage inequality and educational attainment.
} 


\subsection{Demographics}

At each date, some individuals die and a new generation appears. Households reaching age 15 at year $t$ belong to generation $t$. The size of the young generation increases over time at an exogenous growth rate:

$$
N_{0, t+1}=N_{0, t} m_{t}
$$

where $N_{0, t}$ measures the initial size of generation $t$ and $m_{t}$ is one plus the demographic growth rate, including both fertility and migration.

Each household lives a maximum of 8 periods $(a=0, \ldots, 7)$ but face a cumulative survival probability decreasing with age. The size of each generation declines deterministically through time. However, this decline is attenuated by immigration flows:

$$
N_{a, t+a}=N_{0, t} \beta_{a, t+a}+M_{a, t+a}
$$

where $0 \leq \beta_{a, t+a} \leq 1$ is the fraction of generation $t$ alive at age $a$ (hence, at period $t+a$ ) and $M_{a, t+a}$ is the stock of migrants of age $a$. We also have $\beta_{0, t}=1$. Obviously, the total population at time $t$ amounts to $N_{t}=\sum_{a=0}^{7} N_{a, t}$.

The demographic growth rate, immigration flows and the survival probability vector vary over time. Taking account of immigration flows enables us to use official demographic observations and projections.

\subsection{Preferences}

Individuals have an uncertain lifetime duration, i.e. a probability to die at the end of each period of life. In the spirit of Arrow-Debreu, we postulate the existence of a market for every contingent consumption. These markets open before the resolution of uncertainty: each individual has the possibility to insure himself against uncertainty at the beginning of his life. Hence, the problem of agents born at time $t$ is to select a consumption contingent plan and the duration of his education in order to maximize his expected utility subject to his intertemporal budget constraint, given the sequence of contingent wages and prices. 
The expected utility function is assumed to be time-separable and logarithmic:

$$
E\left(U_{t}\right)=\sum_{a=0}^{7} \beta_{a, t+a} \ln \left(c_{a, t+a}\right)
$$

where $c_{a, t+a}$ is the consumption of generation $t$ at age $a$.

The budget constraint requires equality between the expected value of expenditures and the value of income. The expected value of income incorporates education decisions, public transfers and a mandatory retirement age. For a standard household born with age 0 at time $t \ldots \infty$, it may be written as

$$
\sum_{a=0}^{7} p_{a, t+a}\left[c_{a, t+a}\left(1+\tau_{t+a}^{c}\right)-T_{a, t+a}\right]=\sum_{a=0}^{7}\left(\omega_{a, t+a}^{L}+\omega_{a, t+a}^{E} e_{a, t+a}+\omega_{a, t+a}^{H} h_{a, t+a}\right) \ell_{a, t+a}
$$

where $\tau_{t+a}^{c}$ is the consumption tax rate at period $t+a ; p_{a, t+a}$ is the price of one unit of good in case he/she is alive at age $a ; T_{a, t+a}$ denotes the amount of transfer received at age $a$ including education benefits, pensions and other transfers (health care, family allowances, social benefits...); $\ell_{a, t+a}$ measures labor supply at age $a$; raw labor, education and experience are supplied at net-of-taxes contingent wages $\omega_{a, t+a}^{L}, \omega_{a, t+a}^{H}$ and $\omega_{a, t+a}^{E}$.

We can also define the implicit asset holdings $s_{a, t+a}$ of each cohort as follows:

$$
\begin{aligned}
p_{0, t} s_{0, t}= & \left(\omega_{0, t}^{L}+\omega_{0, t}^{E} e_{0, t}+\omega_{0, t}^{H} h_{0, t}\right) \ell_{0, t}-p_{0, t}\left[c_{0, t}\left(1+\tau_{t}^{c}\right)-T_{0, t}\right] \\
p_{a, t+a} s_{a, t+a}= & p_{a-1, t+a-1} s_{a-1, t+a-1}+\left(\omega_{a, t+a}^{L}+\omega_{a, t+a}^{E} e_{a, t+a}+\omega_{a, t+a}^{H} h_{a, t+a}\right) \ell_{a, t+a} \\
& -p_{a, t+a}\left[c_{a, t+a}\left(1+\tau_{t+a}^{c}\right)-T_{a, t+a}\right]
\end{aligned}
$$

For a household already living at the initial date, i.e. with age $j=1 \ldots 6$ at date 0 , the budget constraint is:

$$
\begin{aligned}
& \sum_{a=j}^{7} p_{a, t+a}\left[c_{a, t+a}\left(1+\tau_{t+a}^{c}\right)-T_{a, t+a}\right]=p_{j-1, j-1} s_{j-1,-1} \\
& +\sum_{a=j}^{7}\left(\omega_{a, t+a}^{L}+\omega_{a, t+a}^{E} e_{a, t+a}+\omega_{a, t+a}^{H} h_{a, t+a}\right) \ell_{a, t+a} .
\end{aligned}
$$

The variable $s_{j-1,-1}$ represents the initial asset holdings of this individual. This budget 
constraint is also the one of a migrant entering the country at age $j$. For simplicity, we assume that migrants of each generation have the same characteristics as a native household and have the same implicit wealth, experience and education.

\subsection{Education and experience}

The vector of labor supply for generation $t$ (defining labor supply at all ages) is

$$
\bar{\ell}_{t}=\left(q_{t}\left(1-u_{t}\right), q_{t+1}, q_{t+2}, q_{t+3}, q_{t+4}\left(1-\alpha_{t+4}\right), 0,0,0\right)
$$

where $q_{t}$ is the exogenous participation rate at time $t, 0 \leq u_{t} \leq 1$ measures the endogenous time invested in education in the first period of life and $\alpha_{t+4}$ stands for the (exogenous) time spent in retirement in the fifth period of life (i.e. between age 55 and age 65). The variable $q_{t}$ will be useful to capture the rise in women's participation rates in the labor market.

The education decision made in the first period of life is extremely important since it completely determines the vectors of experience, skills, education subsidies and public transfers for generation $t$. Following Wasmer (2001b), the individual stock of experience sums up past participation rates on the labor market. The stock of education transforms education investment when young into labor efficiency according to a decreasing return function. Public transfers sum up education subsidies, pension benefits and other transfers. These vectors are written as

$$
\begin{aligned}
\bar{e}_{t}= & \left(0,\left(1-u_{t}\right) \theta_{e}^{1} q_{t},\left(1-u_{t}\right) \theta_{e}^{2} q_{t}+\theta_{e}^{1} q_{t+1},\left(1-u_{t}\right) \theta_{e}^{3} q_{t}+\theta_{e}^{2} q_{t+1}+\theta_{e}^{1} q_{t+2}\right. \\
& \left.\left(1-u_{t}\right) \theta_{e}^{4} q_{t}+\theta_{e}^{3} q_{t+1}+\theta_{e}^{2} q_{t+2}+\theta_{e}^{1} q_{t+3}, 0,0,0\right)
\end{aligned}
$$

where $\theta_{e}^{a} \in(0,1)$ represents one minus the depreciation of experience over the lifetime;

$$
\bar{h}_{t}=\left(0, \epsilon u_{t}^{\psi}, \epsilon u_{t}^{\psi}, \epsilon u_{t}^{\psi}, \epsilon u_{t}^{\psi}, 0,0,0\right)
$$

where $\epsilon>0$ and $\psi \in(0,1)$ are two parameters of the educational technology;

$$
\begin{aligned}
\bar{T}_{t}= & \left(v_{t} q_{t} u_{t} \omega_{0, t}^{L}+\gamma_{0} g_{t}, \gamma_{1} g_{t+1}, \gamma_{2} g_{t+2}, \gamma_{3} g_{t+3},\right. \\
& \left.\alpha_{t+4} b_{t+4}+\gamma_{4} g_{t+4}, b_{t+5}+\gamma_{5} g_{t+5}, b_{t+6}+\gamma_{6} g_{t+6}, b_{t+7}+\gamma_{7} g_{t+7}\right),
\end{aligned}
$$


where $v_{t}$ is the rate of subsidy on the cost of education, $b_{t}$ is the pension benefit allocated to each full-time retiree at period $t$ and $\gamma_{a} g_{t}$ is the amount of age-related transfer made by the government to agents of age $a^{2}$. The parameter $\gamma_{a}$ describes the share of total transfer $g_{t}$ in favor of age $a$.

\subsection{Technology}

At each period of time, a representative firm uses labor in efficiency units $\left(Q_{t}\right)$ and physical capital $\left(K_{t}\right)$ to produce a composite good $\left(Y_{t}\right)$. We assume a Cobb-Douglas production function with constant returns to scale:

$$
Y_{t}=A_{t} K_{t}^{1-\varphi} Q_{t}^{\varphi}
$$

where $\varphi$ measures the share of wage income in the national product, and $A_{t}$ is an exogenous process representing total factor productivity.

The quantity of efficiency units of labor combines physical labor supply and human capital according to a Cobb-Douglas transformation function. Human capital is itself a combination of experience and education according to a CES nested transformation function. Formally, we have

$$
Q_{t}=L_{t}^{1-\delta}\left[\mu E_{t}^{\rho}+(1-\mu) \Theta_{t} H_{t}^{\rho}\right]^{\delta / \rho}
$$

where $L_{t}$ measures the input of manpower at time $t ; E_{t}$ measures the input of experience; $H_{t}$ is the input of education; $\delta$ is a parameter representing the importance of human capital in the determination of labor income; $1-\rho$ is the inverse of the elasticity of substitution between experience and education and $\mu$ is a parameter of preference for experience. Finally $\Theta_{t}$ is an exogenous skill biased technical progress.

We assume that workers belonging to different age groups are not perfect substitutes, because they have a different education/experience mix. However, the stocks of education and experience are homogeneous. The interest of this approach is that it is independent of the number of periods of life considered. If we had a model with generations living 55 periods, the production function (11) would remain unchanged. This is an advantage of our framework compared to Card and Lemieux (2001), who aggre-

\footnotetext{
${ }^{2}$ This variable only capture transfers which can be used for private consumption.
} 
gate different age-groups specific human capital within a CES production function. In their approach, the number of embedded CES functions depends on how many groups they are.

The representative firm behaves competitively on the factor markets and maximizes profits:

$$
Y_{t}-\left(r_{t}+d\right) K_{t}-w_{t}^{L} L_{t}-w_{t}^{H} H_{t}-w_{t}^{E} E_{t}
$$

where $d$ is the depreciation rate of physical capital.

\subsection{The public sector}

The government issues bonds and levies taxes on labor earnings $\left(\tau_{t}^{w}\right)$, consumption expenditures $\left(\tau_{t}^{c}\right)$ and capital income $\left(\tau_{t}^{k}\right)$ to finance public transfers and general public consumption. Five types of spending are distinguished: education subsidies, social security benefits, other transfers (health care, family allowance, social benefits), non age-specific general consumption expenditure and interest payments on public debt. The government budget constraint may be written as

$$
\begin{aligned}
& \tau_{t}^{w}\left(w_{t}^{L} L_{t}+w_{t}^{E} E_{t}+w_{t}^{H} H_{t}\right)+\tau_{t}^{c} C_{t}+\tau_{t}^{k} r_{t} K_{t}+D_{t+1}-\left(1+r_{t}\right) D_{t} \\
= & N_{0, t} v_{t} q_{t} u_{t} w_{t}^{L}\left(1-\tau_{t}^{w}\right)+\sum_{a} N_{a, t} \gamma_{a} g_{t}+\vartheta_{t} Y_{t}+\left(N_{4, t} \alpha_{t}+\sum_{a=5}^{7} N_{a, t}\right) b_{t}
\end{aligned}
$$

where $D_{t}$ denotes the public debt at the beginning of period $t ; \vartheta_{t}$ is the share of nontransfer public consumption in GDP and $\gamma_{a} g_{t}$ is the amount of transfer per capita allocated to individuals of age $a$.

Several scenarios can be considered to balance this budget constraint. The budget can be balanced through tax adjustments, expenditure adjustments or changes in the public debt. We assume in the sequel that the path of debt is given and the tax rate $\tau_{t}^{w}$ adjusts to balance the budget.

\subsection{Equilibrium}

At each date, the composite good is taken as numeraire. The spot price is thus normalized to one: $p_{t}=1$. We denote by $r_{t+1}$ the interest rate between dates $t$ and $t+1$, the 
appropriate discount factor applied to age- $a$ income and spending is given by

$$
R_{a, t+a} \equiv \prod_{s=t+1}^{t+a}\left(1+r_{s}\left(1-\tau_{s}^{k}\right)\right)^{-1}
$$

where, by convention, $R_{0, t}=1$. Spot gross wages at time $t+a$ are denoted by $w_{t+a^{\prime}}^{L}$ $w_{t+a}^{H}$ and $w_{t+a}^{E}$. They corresponds to the marginal productivities of labor components, as shown below.

Since there is perfect competition on the insurance market, the contingent prices are related to the spot prices through a set of no arbitrage conditions. The equilibrium (discounted) contingent prices of the consumption good at time $t$ are given by:

$$
p_{a, t+a}=R_{a, t+a} \beta_{a, t+a} p_{t+a}=R_{a, t+a} \beta_{a, t+a}
$$

Equilibrium (discounted) contingent net wages are:

$$
\begin{aligned}
& \omega_{a, t+a}^{L}=R_{a, t+a} \beta_{a, t+a} w_{t+a}^{L}\left(1-\tau_{t+a}^{w}\right) \\
& \omega_{a, t+a}^{E}=R_{a, t+a} \beta_{a, t+a} w_{t+a}^{E}\left(1-\tau_{t+a}^{w}\right) \\
& \omega_{a, t+a}^{H}=R_{a, t+a} \beta_{a, t+a} w_{t+a}^{H}\left(1-\tau_{t+a}^{w}\right)
\end{aligned}
$$

where $\tau_{t+a}^{w}$ denotes the rate of tax on labor income at time $t$. The originality of the model is that labor income consists of three components: manpower, experience and education. Equivalently, individual gross wages are the sum of these three elements so that a tax on labor income $\tau_{t}^{w}$ affects similarly all wage components.

The equilibrium condition on the goods market writes as follows:

$$
Y_{t}+K_{t}^{\star}=\underbrace{\sum_{a=0}^{7} N_{a, t} c_{a, t}}_{C_{t}}+\underbrace{K_{t+1}-(1-d) K_{t}}_{I_{t}}+\underbrace{\vartheta_{t} Y_{t}}_{G_{t}}
$$

where $K_{t}^{\star}$ represents the asset holdings brought into the country by migrants. It is given by:

$$
K_{t}^{\star} \equiv\left(1+r_{t}\right) \sum_{a=1}^{8} s_{a-1, t-1}\left(N_{a-1, t-1}-N_{0, t-a} \beta_{a-1, t-1}\right)
$$

where the terms between brackets is the flow of migrants between date $t$ and date $t-1$. 
To avoid modelling the specific behavior for migrants over their life, we consider that they enter the country with an asset level $s_{a, t-1}$ given by (3)-(4), i.e. equivalent to that of the natives of the same age.

The labor market equilibrium equalizes the demand for labor from firms $L_{t}, E_{t}$ and $H_{t}$ to the sum of the individual supplies:

$$
L_{t}=\sum_{a=0}^{7} N_{a, t} \ell_{a, t}, \quad E_{t}=\sum_{a=0}^{7} N_{a, t} \ell_{a, t} e_{a, t}, \quad H_{t}=\sum_{a=0}^{7} N_{a, t} \ell_{a, t} h_{a, t}
$$

Definition 1 (Competitive equilibrium) Given a demographic structure summarized by $\left\{N_{a, t}\right\}_{a=0 . .7, t \geq 0}$, an initial distribution of education $\left\{u_{-j}\right\}_{j=1 . .4}$ and wealth $\left\{s_{j-1,-1}\right\}_{j=1 . .7, a}$ competitive equilibrium is

- $a$ vector of individual variables $\left\{c_{a, t}, u_{t}, \ell_{a, t}, e_{a, t}, h_{a, t}\right\}_{a=0 . .7, t=a .++\infty}$ such that utility (1) is maximized subject to the constraints (2), (6), (7), (8), and (9);

- a vector of individual variables $\left\{c_{a, 0}, \ell_{a_{0}}, e_{a, 0}, h_{a, 0}\right\}_{a=1 . .7, t=0 . .7-a}$ such that utility (1) of the first old generations is maximized subject to the constraints (5), (6), (7), (8), and (9);

- a vector of firms' variables $\left\{K_{t}, L_{t}, E_{t}, H_{t}\right\}_{t \geq 0}$ such that profits (12) are maximized subject to technology (10)-(11);

- a vector of taxes $\tau_{t}^{w}$ balancing the budget of the government (13);

- a vector of contingent prices $\left\{p_{a, t+a}, \omega_{a, t+a}^{L}, \omega_{a, t+a}^{E}, \omega_{a, t+a}^{H}\right\}_{a=0.7, t \geq 0}$ such that the no arbitrage conditions (14)-(15) hold;

- a vector of interest factor and gross wages $\left\{r_{t}, w_{t}^{L}, w_{t}^{E}, w_{t}^{H}\right\}_{a=0 . .7, t \geq 0}$ such that the goods and labor markets are in equilibrium, i.e. (16)-(17) hold, and

$$
K_{0}=\sum_{a=1}^{8} N_{a, 0} s_{a-1,-1}-D_{0}
$$

for the first period.

\subsection{Optimality conditions}

Since there is no disutility of labor, the problem of households is separable. 
- Individuals first maximize the expected value of income - right hand side of (2) with respect to educational investment $u_{t}$.

- Then, in a second step, they maximize the expected utility function and select the optimal contingent plan subject to the budget constraint in which the education investment is set to its optimal value.

The optimal education investment is given by

$$
u_{t}^{*}=\left(\frac{\epsilon \psi \sum_{a=1}^{4}\left[\omega_{a, t+a}^{H} \theta_{h}^{a} q_{t+a} \ell_{a, t+a}\right]}{\left(1-v_{t}\right) q_{t}\left[\omega_{0, t}^{L}+\omega_{0, t}^{H}\right]+\sum_{a=1}^{4}\left[\omega_{a, t+a}^{E} \theta_{e}^{a} q_{t+a} \ell_{a, t+a}\right]}\right)^{\frac{1}{1-\psi}}
$$

Obviously, the optimal education investment balances the marginal gain of education at the numerator (future path of net return on education) and the marginal cost of education at the denominator; the marginal costs includes both the foregone wage when young and foregone net return on experience.

Maximizing utility with respect to the levels of consumption determines the law of motion of contingent consumption expenditures over the lifetime:

$$
c_{a+1, t+a+1}=\frac{\left(1+r_{t+1}\right)\left(1+\tau_{t}^{c}\right)}{\left(1+\tau_{t+1}^{c}\right)} c_{a, t+a} \quad \forall a=0, \ldots, 6
$$

Substituting (18) and (19) into the budget constraint (2) gives the optimal level of consumption in the first period of life. The aggregated consumption at period $t$ then amounts to $C_{t}=\sum_{a} N_{a, t} c_{a, t}$.

The profit maximization by firms requires the equality of the marginal productivity of each factor to its rate of return. They may be written as

$$
\begin{aligned}
r_{t} & =(1-\varphi) A_{t} Y_{t} / K_{t}-d \\
w_{t}^{L} & =\varphi(1-\delta) A_{t} Y_{t} / L_{t} \\
w_{t}^{E} & =\varphi \delta \mu A_{t} K_{t}^{1-\varphi} Q_{t}^{\varphi-1} L_{t}^{1-\delta} E_{t}^{\rho-1}\left[\mu E_{t}^{\rho}+(1-\mu) \Theta_{t} H_{t}^{\rho}\right]^{\delta / \rho-1} \\
w_{t}^{H} & =\varphi \delta(1-\mu) \Theta_{t} A_{t} K_{t}^{1-\varphi} Q_{t}^{\varphi-1} L_{t}^{1-\delta} H_{t}^{\rho-1}\left[\mu E_{t}^{\rho}+(1-\mu) \Theta_{t} H_{t}^{\rho}\right]^{\delta / \rho-1}
\end{aligned}
$$


Clearly, the supply of experience and the supply of education influence the ratio of the rates of return for these two factors:

$$
\frac{w_{t}^{H}}{w_{t}^{E}}=\frac{1-\mu}{\mu}\left[\frac{H_{t}}{E_{t}}\right]^{\rho-1} \Theta_{t} .
$$

If $\rho$ is lower than one, and increase in the stock of experience stimulates the rate of return on education. Any technical change $\Theta_{t}$ will also affect the ratio.

Given the hypothesis of constant returns to scale, national product is equal to the sum of capital income and labor income:

$$
Y_{t}=\left(r_{t}+d\right) K_{t}+\left(w_{t}^{L} L_{t}+w_{t}^{E} E_{t}+w_{t}^{H} H_{t}\right)
$$

\section{Calibration}

Two model economies are calibrated (one for France and one for the US) in order to reproduce some characteristics of these countries. Calibration implies using data for observed exogenous variables, fixing some constant parameters, and chosing paths for the unobserved exogenous variables in order to match a series of characteristics. Calibration is not focused on reproducing characteristics of a given steady state, where all the interesting information on population history, experience stocks and skills per age group would be lost. Instead, the equilibrium is computed as a transition from one steady state in 1900 to one another in 2250. By starting in 1900, the stocks of education and experience around 1960 reflect the correct history of the population. We focus our attention on the year 2000 (i.e. the period 1995-2004) to target some characteristics of the data.

\subsection{Observed exogenous variables}

Demography. Past and future population shares per age are taken from official demographic institutes. For France, we use observations and forecasts from INED (2001) and INSEE (1995). For the US, data and forecasts are taken from the Population Division of the US Census Bureau. As for demographic projections, we use the central scenario for both countries. For France and US, the population aged 95 and more is not taken 
into account. The data are presented in appendix A.

Education and participation rates. Appendix B presents the data on education and participation rates. The time invested in education is computed using school attendance measures and educational attainment. The old age participation rate $\alpha$ is computed using the effective retirement age data. Overall participation rates $q_{t}$ are normalized to 1 in 2000 and computed from Wasmer (2001a).

Public finance. In our model, we have three proportional taxes: the labor income tax, the capital income tax and indirect taxes. We also distinguish two types of government spending (net of debt charges): non age-specific public consumption and age-specific transfers taken from generational accounting studies. Social security benefits and other individual transfers evolve exogenously. The path of public debt is given exogenously, and the labor income tax adjust to balance the budget. Appendix $\mathrm{C}$ describes the data sources for these variables.

\subsection{Parameters}

A set of parameters is set a priori, the same for both countries. By doing so, we minimize the amount of assumed differences between France and the US. The labor share in output, $\varphi$, is set to 0.7 , (this value is commonly used in calibrated model of the US economy. In France, the labor share equals 0.693 in 1995, according to INSEE.) The depreciation rate of capital $d$ equals 0.4 . This value implies an annual depreciation rate of $5 \%$. The depreciation rate of experience will follow the median hypothesis of Wasmer (2001b), i.e. an annual rate of $3 \%$, independent of age. This yields $\theta_{e}^{1}=0.737$, $\theta_{e}^{2}=\left(\theta_{e}^{1}\right)^{2}$ etc ... The parameter $\mu$ in the production function is a scale parameter of no importance given the later choice of $\Theta_{t}$; it is set to 0.5 . Two parameters are important in shaping the wage profile per age: the share of raw labor in labor income $(1-\delta)$ is set to 0.4 , and the scale parameter in the production function of human capital $\epsilon$ is set to 1.2. They will both deliver an adequate wage profile (see below).

The two elasticity parameters are of special importance. The parameter $\rho$ determines substitution between education and experience. It is set to -0.9 according to Wasmer's (2001a) estimates, implying a low substitutability $(1 /(1-\rho)=0.52)$ between the two components of human capital. The parameter $\psi$ is the elasticity of education capital to investment in education. It should be calibrated using the estimated elasticity 
of future earnings with respect to additional schooling (see e.g. Psacharopoulos (1994) for a survey of these elasticities); we take the value $\psi=0.6$ which is in accordance with a return to an additional year of schooling of $11.5 \%$, assuming that this additional year of schooling raises education expenditure by $20 \%$.

\subsection{Identification of unobserved exogenous variables}

Explaining skill premium and educational investment requires identifying exogenous variables for which time series data are not available. Our methodology follows two steps. We first define a baseline scenario where we use the model to identify the unobserved exogenous variables. In this step, the skill premium and educational investment will be matched exactly by the model. In the second step, we compute the hypothetical path of the skill premium and education investment by keeping constant different exogenous variables; by doing so we evaluate the relative contribution of each exogenous process on the endogenous outcomes.

There are five unobserved exogenous variables: total factor productivity, $A_{t}$, the rate of subsidy on education expenditures, $v_{t}$, the skill-biased technical progress, $\Theta_{t}$, the level of pension benefit, $b_{t}$, and the scale of the age-specific transfer profile, $g_{t}$. These five exogenous processes are chosen so as to match available time series data for five endogenous variables which are closely related to the unknowns: the GDP growth rate, the share of social security and other transfers in GDP, the education investment of young cohorts and the return on education. The return on education is based on the data provided in the introduction. For the skill premium prior to 1960, we consider it constant at its 1960 value. $^{3}$

Basically, our identification process implies swapping five exogenous variables for five endogenous variables and solving the identification step with the algorithm proposed by Laffargue (1990) and Boucekkine (1995). ${ }^{4}$ The identification of the education policy captures changes in the characteristics of the education system. The skill-biased technical progress captures changes in the productivity of skills, affecting the demandside of the labor market. The technical change is allowed to differ across countries.

\footnotetext{
${ }^{3}$ An alternative is to use Goldin and Katz (1999) who provide data since 1920; unfortunately, such estimates are not available for France.

${ }^{4}$ Our identification process resembles Sims (1990) backsolving method for stochastic general equilibrium models. We use a similar idea of treating exogenous processes as endogenous, not to solve a model, but as a calibration device in a deterministic framework.
} 
Our backsolving identification procedure allows to calibrate the model "dynamically". This is much better and rigorous than calibrating on a hypothetical steady state (in 1900 or in 2250) and re-scaling exogenous variables to obtain reasonable outcomes at a given date, as it is usually done in Auerbach and Kotlikoff (1987) tradition.

To match labor market trends over the period 1960-2000, we need to specify agents' expectations about the future. The expectations over the period 2010-2080 are indeed important to determine the optimal behavior over the period 1960-2000. We now describe our main assumptions:

- the shares of public pensions and other transfers in GDP are kept constant (this usually requires individual benefits to grow at a lower pace than labor productivity). This assumption is in line with the US projections of the Congressional Budgetary Office;

- the public debt - GDP ratio is constant after 2000;

- between 2000 and 2030, retirement age will gradually increase from age 58.7 to 60 in France, reflecting current policy changes. In the US, retirement age is kept constant at age 62.5;

- the US educational attainment (among the population aged 25 and more) matches US official projections. The educational attainment projections are reported in Cheeseman Day and Bauman (2000). They are based on separate educational attainment rates by race, ethnic groups, gender, age and nativity status. We opt for the "high" projection scenario in which the proportion of population aged 30 to 35 and graduating from high school and more grows from $89.6 \%$ in 2003 to $94.8 \%$ in 2028 (from $59.2 \%$ to $70.2 \%$ for College and from $28.7 \%$ to $32.2 \%$ for Bachelor's). Compiling these numbers to obtain the average time devoted to education between age 15 and 24, it appears that the time invested in schooling increases from $59.1 \%$ in 1990 to $67.0 \%$ in 2030 . We consider that French educational attainment of future young cohorts will converge toward the US level between 1990 and 2035; it implies that time invested in education will grow from 51.0\% in 1990 to $67.0 \%$ between 1990 and 2030 .

- in both countries, the growth rate of GDP linearly converges within two decades toward a long-run level of $20 \%$ per decade. 
- in both countries, the skill premium is kept at its last observed value; as this conjecture is not based on any available information, section 5 will provide a sensitivity analysis to this assumption.

\subsection{Identified shocks}

Before doing the counterfactual experiments, let us briefly examine the result of our identification process. Figure 3 depicts the implicit education subsidies $v_{t}$ between 1950 and 2050 and the identified skill-biased technical progress, $\Theta_{t}$.

Education policies are very different. Between 1960 and 1980, the French educational policy was highly expansionary while in the US, it became strongly discouraging in the early seventies and the eighties. There are several stylized facts explaining this difference. In France, student strikes of May 1968 initiated a deep debate on the role of educational policies. In the eighties, the Government announced its objective of an $80 \%$ pass rate for the baccalauréat. Various specific policies have been intended to decrease the cost of education. In the US, OECD indicators show that the share of public spending on total education expenditure fell over time. It decreased from $88 \%$ in 1988 to $75 \%$ in 1995 ( $47 \%$ only for higher education programs). It should be noted that France's corresponding percentages were $88 \%$ in 1988 (as in the US) and $92 \%$ in 1995. After 2000, expected educational policies became rather stable.

This difference in education policies is corroborated by considering the ratio of the price index of education goods (Tuition, other school fees, etc.) to the overall price index. Figure 4 plots these "relative prices" of education for both countries. For the US (right panel), the ratio of the two price indexes show that the cost of education in terms of the aggregate consumption good doubled between 1978 and 2002, reflecting sharp increases in tuition fees. For France, there is no decline, but the rise in the cost of education is much smaller.

Looking deeper into the US cost structure of education (from the Department of Education), we observe that nominal tuition and required fees have increased by a factor of 6.10 from 1976 to 2000 in private institutions, and by a factor of 5.42 in public institutions. The cost of dormitory rooms has increased by a factor of 5.19 in private schools (4.41 in public schools). The cost of boarding has increased by a factor of 3.78 in private schools (3.37 in public schools). Over the same period the overall price index 
Figure 3: Identified implicit education subsidy $v_{t}$ and biased technical change $\Theta_{t}$
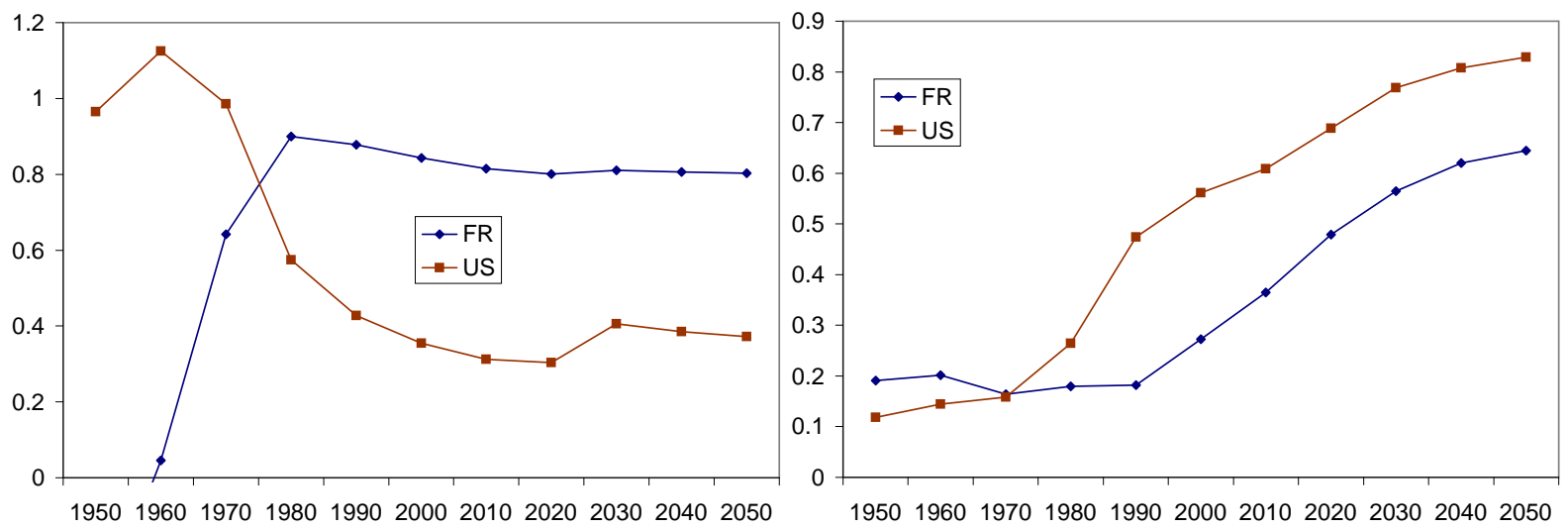

Figure 4: Relative price of education: France and the US
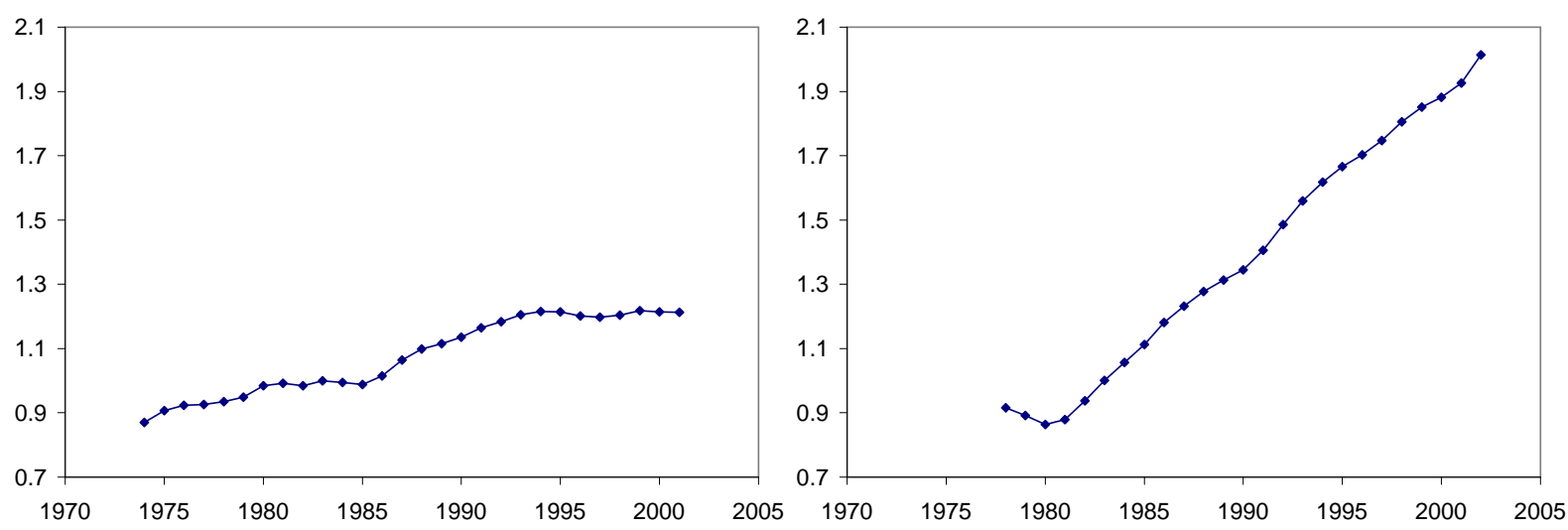

Note: $1985=1$ 
increased by a factor 2.72 .

Going back to Figure 3, we observe that, between 1970 and 2000, skill-biased technical change was strong in the US but not in France. In the literature, skill-biased technical change has been related to investment in information technology and/or to patterns of international trade. As far as information technologies are concerned, data presented in Kaufman, Luzio, and Dunaway (2001) display a pattern similar to our measured technical progress: the percentage of GDP allocated to investment in information technology rose in the US from 7.5\% to 9\% between 1992 and 1999, while it stayed constant in France, around 6\%. Moreover, Card, Kramarz, and Lemieux (1999) report that the proportion of workers using a computer is somewhat higher in the US than in France (37.4\% in US in 1989 and 34\% in France in 1991). Machin and Reenen (1998) relate the skilled-biased technical change to R\&D intensity. Their data show that the share of R\&D in GDP increased both in France and the US, but stays 3\% higher in the US over the period 1973-1989. Concerning international trade, Card, Kramarz, and Lemieux (1999) show that the US also experienced a larger increase in the Imports/GDP ratio from less developed countries between 1973 and 1993 (the higher are the imports from low-wage countries, the more the country is specialized in high skill activities).

After 2000, our model exhibits a convergence process between the countries even if, in the long-run, the skill bias keeps stronger in the US. ${ }^{5}$ This result is consistent with the vast literature on the technical leadership of the US economy. Since 1870, Europe growth performances have been driven by delayed technological innovation simply accomplished by mimicking the US achievement. According to Gordon (2002), the current dominance of the US in information and communications technology (ICT) can be related to issues such as patent protection, securities regulation, the role of venture capital and the large funding policy of hi-tech companies.

Following our identification procedure, it takes between 20 and 30 years for France to adopt US knowledge. This is somewhat lower than the delay observed for the major past innovations. The transformation of Western Europe achieved by electricity and internal combustion began in the 1950s, almost 40 years after than in the United States. Similarly, the percentage of French households owning a car mimicked the equivalent US ratio roughly 40 years later.

\footnotetext{
(2002).

${ }^{5}$ For a model explaining why technological leadership may persist even at steady state, see Cozzi
} 
How can we explain such a delay of 20-30 years? A host of studies have found evidence that the recent skill biased technical progress leads to organizational changes within firms (employees perform a wider range of tasks and have more responsibility). Caroli and Reenen (2001) provide evidence that organizational changes leading to increases in productivity can only be observed in workplaces with high levels of skills. On this basis, they find some support for a stronger skill biased technical change in Britain than in France. Similarly, the US leadership appearing on Figure 3 can be seen as resulting from a higher level of education of the US labor force in the 1970s and 1980s. As shown on figure 10 in the appendix, the educational attainment of young French cohorts in 1990 equals that of US young cohorts in 1970, i.e. 20 years later.

\subsection{Wage and assets profile per age}

The quality of our model depends on its ability to match individual profiles per age. Let us focus on wage and wealth profiles. Figure 5 provides the wage profile per age for the year 2000, comparing for each country the model's outcome with data (INSEE for France and PSID for the US). The concave shape of the profile per age is fully determined by the accumulation and depreciation of experience; no need to assume an exogenous profile as in Auerbach and Kotlikoff (1987). This figure comforts us in the choice of $\delta, \epsilon$ and $\theta_{e}$.

It is usually argued that the standard life cycle model with selfish households does not provide a good description of wealth accumulation after retirement. Figure 6 reports asset profiles per age at time 2000, together with their empirical counterpart (INSEE for France and PSID for the US). It appears that our model matches the profile, except for the very old people (85-94). Hence, there is no need to suppose a pure time preference parameter on top of the mortality rate. The annuity market is also helpful to avoid poverty in the old age.

\subsection{The return to experience}

The return to experience is an endogenous outcome of the model. Figure 7 gives the simulated return to 20 years of experience for France and the US. Combining equation 
Figure 5: Wage profile over age

Wage profile - France 2000

Wage profile - USA 2000

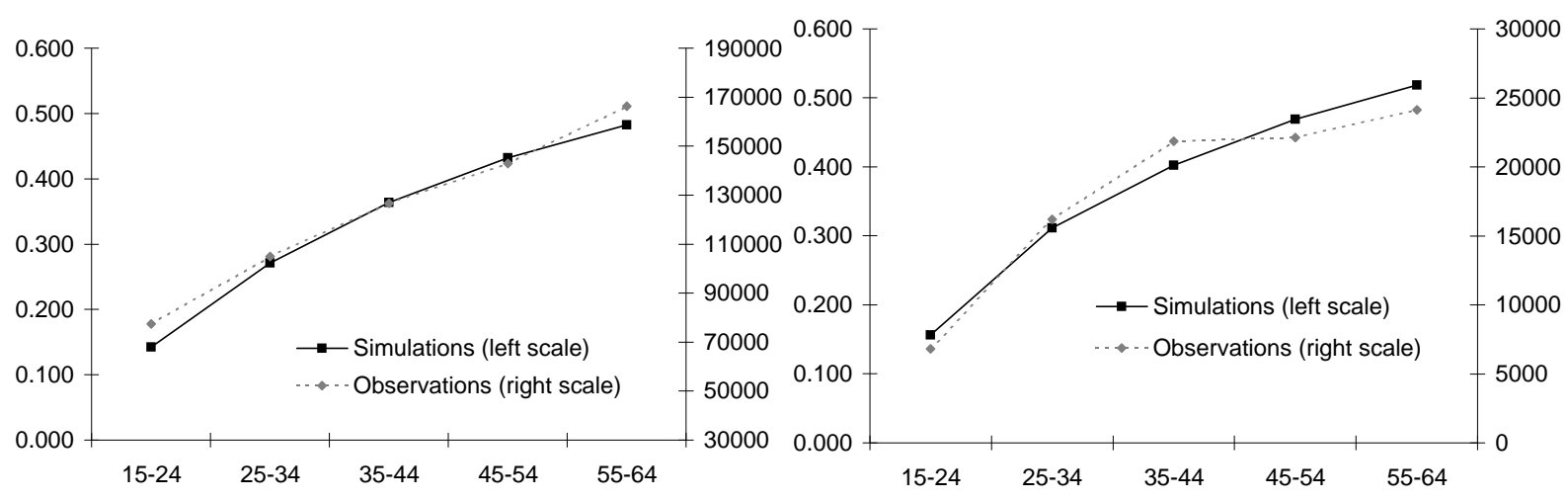

Note: Wages are measured in domestic currencies, current prices

Figure 6: Asset profile over age

Wealth profile - France 2000

Wealth profile - USA 2000

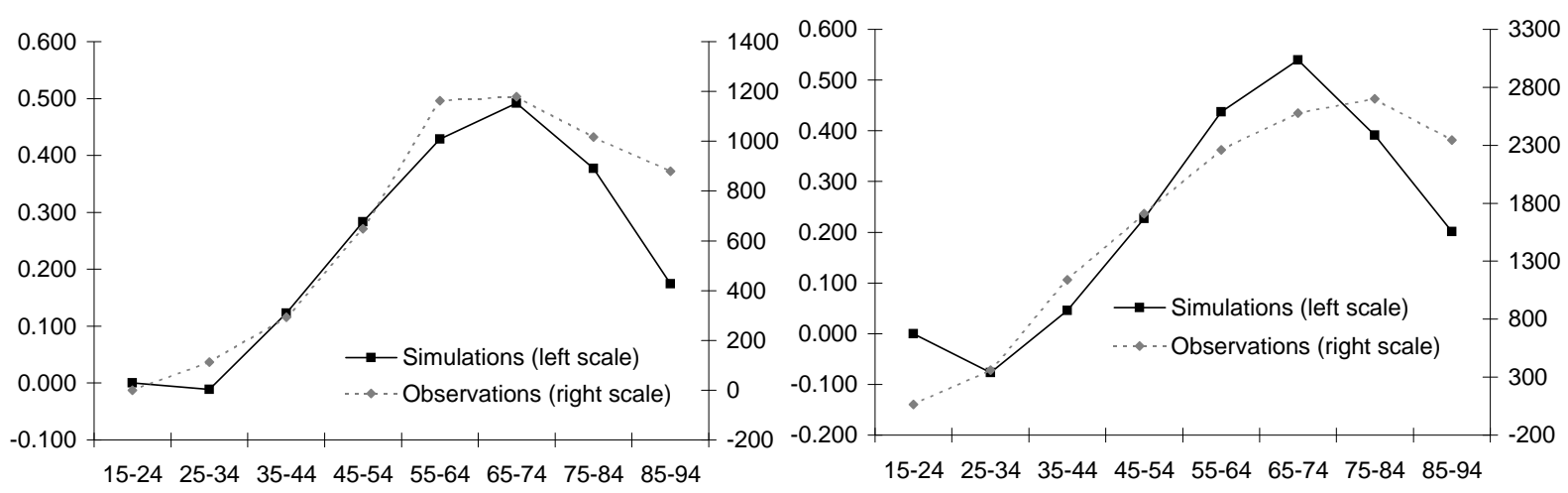

Note: Assets are measured in domestic currencies, current prices 
Figure 7: Simulated return to experience (20 years)

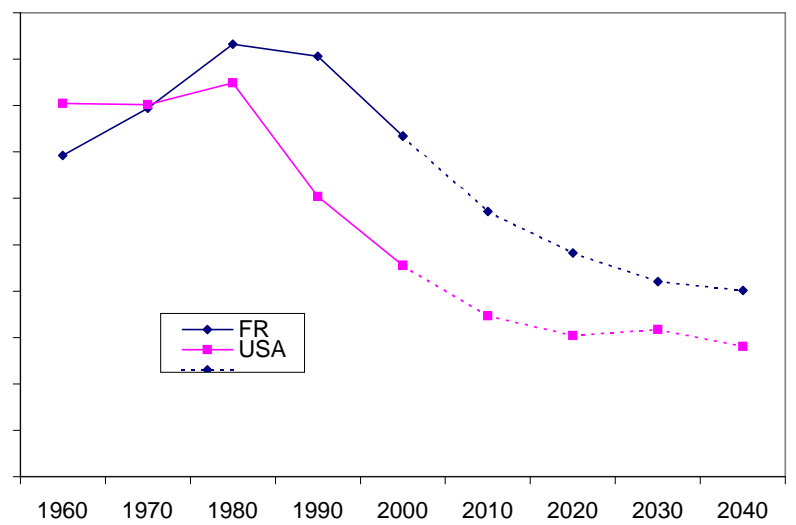

(21) and (22) and using $\rho=-.9$, this return is determined by

$$
\frac{w_{t}^{E}}{w_{t}^{L}}=\frac{\delta \mu}{1-\delta} \frac{L_{t}}{E_{t}} \frac{1}{\mu+(1-\mu) \Theta_{t}\left(\frac{E_{t}}{H_{t}}\right)^{.9}}
$$

which is a decreasing function of $E_{t} / L_{t}$ and $\Theta_{t}$.

Changes in both the population structure per age and technology are the driving forces affecting the experience premium. Between 1960 and 1980, the average experience of workers (as measured by $E_{t} / L_{t}$ ) fell in both countries. As a result, the return to experience increased over that period, which is reflected in Figure 7. Our simulations correctly depict the fact that the experience premium increased more in France than in the US between 1960 and 1980. This difference between the two countries is mainly due to the stronger skill biased technical change in the US. Indeed, the average experience of workers decreases more in the US than in France. Without technical progress (as measured by $\Theta_{t}$ ), the rise in the experience premium would have been stronger in the US. However, the US skill biased technical change did offset an important part of the rise in the experience premium.

Between 1980 and 2020, aging induces a sharp increase in the average experience of workers. This explains why the return to experience starts decreasing in 1980, an evolution which is compatible with Wasmer's numbers presented in Figure 2. For the next decades, our simulations provide a similar time path for both countries. The rise in the stock of experience is lower in France $(+20 \%)$ than in the US $(+30 \%)$ but the 
French skill biased technical change produces its effects after 2000 and reinforces the impact on the experience premium.

\section{Explaining skill premium and education paths}

Our analysis will now rely on counterfactual experiments. We compute six hypothetical paths of skill premia and educational attainment, each path being obtained by keeping one exogenous variable at its level of 1960. The six exogenous variables we consider are: demographics (including mortality, fertility, and migration), skill-biased technical progress, overall participation rate, the effective retirement age, welfare programs, and education subsidies. Such experiment allows us to evaluate the marginal impact of each exogenous variable on endogenous variables. Table 1 provides the contribution of these exogenous variables to the rise in educational attainment for France and the US. Each number represents a cumulated impact on the time devoted to education between age 15 and $24\left(u_{t}\right)$.

Educational attainment increases with life expectancy, skill-biased technical progress, education subsidies and participation rates. In both countries, the impact of the changes in the welfare state policy (taxes and transfers) and in demographics is rather low. The increasing participation rate of women on the labor market explains an important part of education decisions. This is also true for the decrease in effective retirement age, especially in France. The major difference between France and the US concerns the role of educational policies: between 1960 and 1970, the French educational policy became expansionary. The positive impact on education investment was especially strong in the seventies and the eighties; in the US, the discouraging education policy became important in the late seventies and the eighties.

Table 2 provides the contribution of each exogenous variable on the skill premium for France and the US. The skill premium measures the wage increase enjoyed by an individual investing $30 \%$ of his time in education compared to an individual with no education investment between age 15 and 24 :

$$
\frac{w^{H}\left(\epsilon 0.3^{\psi}\right)}{w^{L}}
$$

Since the eighties, demographic shocks have exerted a negative impact on the skill pre- 
Table 1: Explaining the changes in school attendance (deviation from 1960 value) France

US

\begin{tabular}{l|cccc|cccc} 
& 1970 & 1980 & 1990 & 2000 & 1970 & 1980 & 1990 & 2000 \\
\hline \hline Demographics & -0.02 & -0.01 & +0.05 & +0.07 & -0.04 & +0.01 & +0.09 & +0.05 \\
Technical bias & +0.00 & +0.04 & +0.18 & +0.26 & +0.25 & +0.30 & +0.32 & +0.35 \\
Participation rate & +0.02 & +0.06 & +0.09 & +0.11 & +0.04 & +0.07 & +0.09 & +0.09 \\
Early retirement & -0.04 & -0.08 & -0.09 & -0.10 & -0.03 & -0.02 & -0.02 & -0.03 \\
Welfare state & -0.02 & -0.03 & -0.02 & -0.01 & -0.01 & -0.02 & -0.01 & +0.00 \\
Education policy & +0.05 & +0.10 & +0.12 & +0.12 & +0.06 & -0.11 & -0.16 & -0.15 \\
\hline
\end{tabular}

Table 2: Explaining the changes in the skill premium (\% deviation from 1960 value)

\begin{tabular}{l|cccc|cccc} 
& \multicolumn{9}{|c}{ France } & \multicolumn{7}{c}{ US } \\
& 1970 & 1980 & 1990 & 2000 & 1970 & 1980 & 1990 & 2000 \\
\hline \hline Demographics & -0.01 & -0.02 & -0.06 & -0.06 & +0.09 & +0.04 & -0.05 & -0.07 \\
Technical bias & -0.06 & -0.02 & -0.14 & -0.05 & -0.13 & -0.03 & +0.14 & +0.10 \\
Participation rate & -0.02 & -0.05 & -0.08 & -0.11 & -0.02 & -0.05 & 0.08 & -0.08 \\
Early retirement & +0.05 & +0.08 & +0.10 & +0.08 & +0.03 & +0.02 & +0.03 & +0.04 \\
Welfare state & +0.01 & +0.03 & +0.06 & +0.06 & +0.01 & +0.02 & +0.03 & +0.03 \\
Education policy & +0.03 & -0.06 & -0.23 & -0.34 & -0.06 & -0.05 & +0.07 & +0.16 \\
\hline
\end{tabular}

mium in both countries. However, before 1985, the effect of demographics was positive in the US: the impact of the demographic structure on the stock of experience was more important than the stimulating effect on the stock of education. Early retirement had a positive impact on the skill premium as well as did welfare state programs. Two opposite results emerge: first, the educational policies had diverging effects. In France, the expansionary policy stimulated the stock of skills and exerted a negative impact on the skill premium. In the US, the skill premium has been boosted by restrictive policies for the last thirty years; second, the impact of technical shocks was different. In France, the skill-biased technical shock had a slightly negative impact on the skill premium: this is because the effective skill-biased technical change has been very low between 1960 and 1990, but is expected to be strong in the next decades; such expectations have increased the supply of skills, but not the demand yet; hence, the current skill premium is depressed. In the US, the impact of the skill biased technical change 
Figure 8: Sensitivity analysis: bias (top), subsidy (bottom), France (left), US (right)
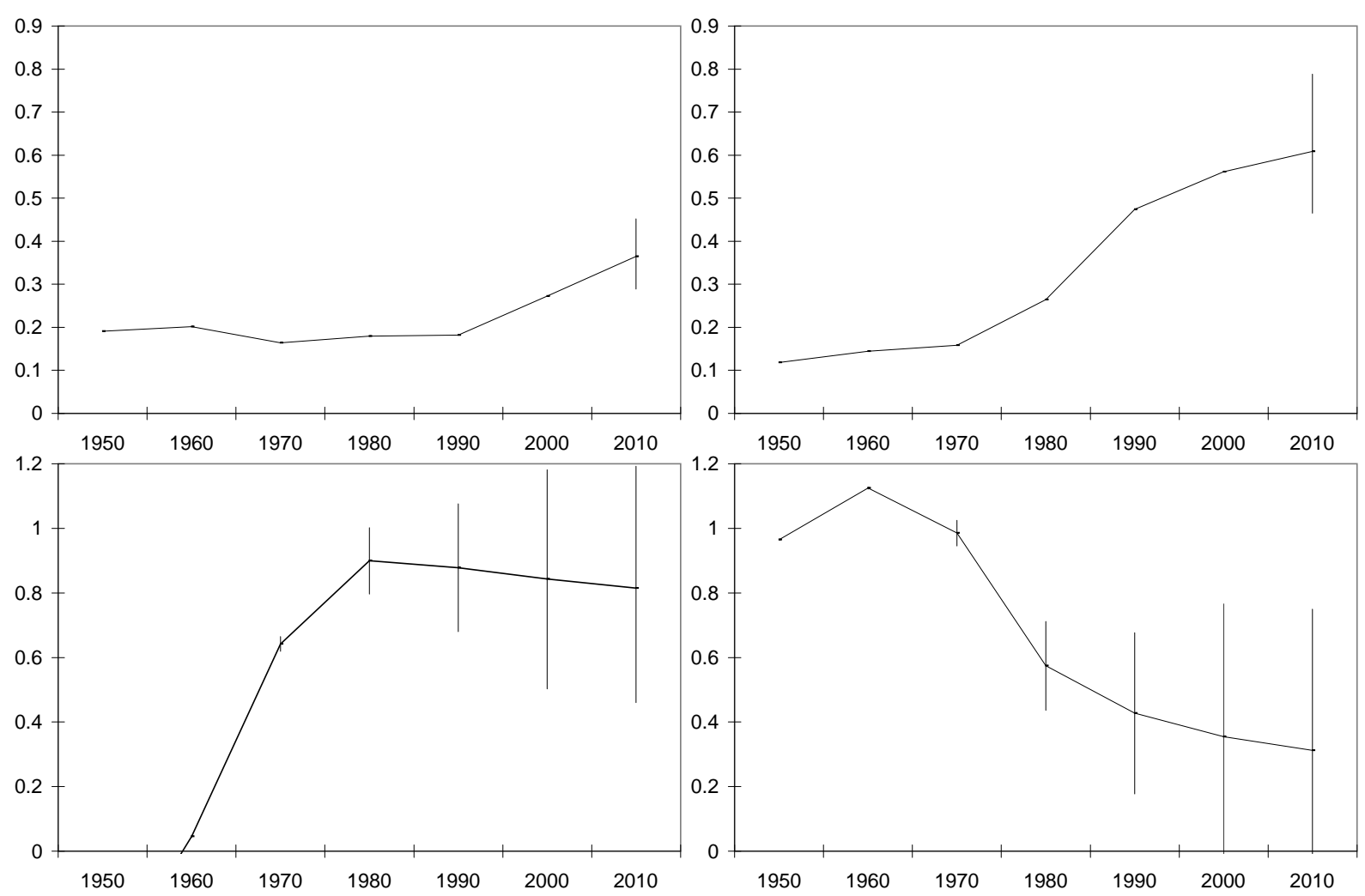

is strongly positive. This is the usual effect put forward a.o. by Machin and Reenen (1998): the technical change has had a clear effect of increasing the relative demand for skilled workers.

\section{Sensitivity analysis}

In this section, we study the sensitivity of the identification procedure to the assumption that the skill premium is constant after the year 2000. For that purpose, we consider two alternative scenarios about the evolution of the skill premium between 2000 and 2050. The first scenario considers an increasing skill premium $(+15 \%$ from 2010 onwards compared to the baseline). The second scenario considers a decreasing skill premium (-15\% from 2010 onwards).

Figure 8 presents the sensitivity of the skill biased technical change and the edu- 
cation subsidy rate and shows that the identified skill bias is highly robust between 1950 and 2000. The bias is only affected by skill premium expectations after 2000. The identified education subsidy rate is more sensitive from the eighties onwards, but especially after 1990. Considering an increasing (a decreasing) skill premium requires a lower (a higher) education subsidy rate to match observed educational attainment. Clearly, our conclusion about the changes in education policy still hold. Between 1960 and 2000, the French educational policy was expansionary. On the contrary, the US policy was less generous over the period 1980-2000 than in 1960. As a consequence, the general picture presented in Tables 1 and 2 remains valid, but the magnitude of the impact of educational policies and technical changes on human capital investments and on the return to skill is likely to be sensitive to skill premium expectations for 1990 and 2000 .

\section{Conclusion}

This paper provides an original model where education and experience are two components of human capital. Education choices are endogenous and households face lifetime uncertainty. This model is used to compute how education choices and returns to skills are affected by demographic changes, welfare, fiscal and educational policies, technical changes, increases in female participation rates, and decreases in the effective retirement age. Exogenous processes for technical progress and private cost of education have been identified by letting the model match observed skill premium and investment in education. We have then proceeded with counterfactual experiments and compute the endogenous path for skill premium and education when each exogenous variable is kept at its 1960 level.

Our method allows us to identify technical and policy shocks affecting the US and the French economies on the post-war period. Between 1970 and 2000, we show that the skill-biased technical change was strong in the US and affected France with a delay. Over the same period, the French educational policy was highly expansionary whilst it progressively became discouraging in the US. We provide several stylized facts explaining these differences.

In terms of educational attainment, the impact of the changes in fiscal policy (taxes and transfers) and in demographics is rather low in both countries. The increasing 
participation rate of females in the labor market explains a part of the rise in investment in education. The major difference between France and the US concerns the role of educational policies: the French educational policy had a positive impact on education investment especially in the seventies and the eighties; in the US, the discouraging education policy became important in the late seventies and the eighties. In accordance with common wisdom, the skill-biased technical bias had a positive effect on education in both countries. In terms of skill premia, two opposite results emerge. First, the educational policies exerted a negative impact in France and a positive impact in the US. Second, the skill-biased technical shock had a low impact in France and a strong impact in the US.

Finally, our model clearly deserves some extensions. It would interesting to mix our supply-side interpretation of experience premium changes with seniority rules and efficiency wage issues. Endogenizing technical changes also appears as a promising issue. Introducing heterogeneity would enable to study the inequality effects of education policies, especially their effects on social mobility. Our model also provides an appropriate framework to compare internal responses to aging (such as increasing the effective retirement age) and external responses (increasing immigration flows) in regards of the labor market equilibrium. We leave these issues for further research.

\section{References}

Auerbach, Alan and Laurence Kotlikoff. 1987. Dynamic Fiscal Policy. New York and Melbourne: Cambridge University Press.

Becker, Gary. 1964. Human capital: A theoretical and empirical analysis, with special reference to education. New York: Columbia University Press.

Blondal, Sveinbjorn and Stefano Scarpetta. 1997. "Early Retirement in OECD Countries: The Role of Social Security Systems." OECD-Economic-Studies 0 (29): 7-54.

Borjas, George. 2001. Heaven's Door: Immigration Policy and the American Economy. paperback edition. Princeton: Princeton University Press.

Boucekkine, Raouf. 1995. "An alternative methodology for solving non-linear forward-looking models." Journal of Economic Dynamics and Control 19 (4): 711734. 
Brown, Carey. 1990. "Episodes in the public debt history of the United States." In Public debt management:t heory and history, edited by Rudiger Dornbusch and Mario Draghi, 229-254. Cambridge: Cambridge University Press.

Card, David and Thomas Lemieux. 2001. "Can Falling Supply Explain the Rising Return to College for Younger Men? A Cohort-Based Analysis." Quarterly Journal of Economics 116 (2): 705-646.

Card, David, Francis Kramarz, and Thomas Lemieux. 1999. "Changes in the Relative Structure of Wages and Employment: A Comparison of the United States, Canada, and France." Canadian Journal of Economics 32 (4): 843-877.

Carey, David and Harry Tchilinguirian. 2000. "Average effective tax rates on capital, labour and consumption." Working Paper 258, OECD.

Caroli, Eve and John Van Reenen. 2001. "Skill biased organizational change? Evidence from a panel of British and French establishments." Quarterly Journal of Economics 116, no. 4.

Cheeseman Day, Jennifer and Kurt Bauman. 2000. "Have we reached the top ? Education attainment projection of the US population." Working Paper 43, US Bureau of Census.

Cozzi, Guido. 2002. "The self-fulfulling international allocation of innovation, inequality and education." University of Rome.

Crettez, Bertrand, Karen Feist, and Bernd Raffelüschen. 1999. "France: generational imbalance and social insurance reform." Generational accounting in Europe. European economy reports and studies, 6 .

Estrade, Marc-Antoine and Claude Minni. 1996. "La hausse du niveau de formation: la durée des études a doublé en cinquante ans."

Gokhale, Jagadeesh, Benjamin Page, and John Sturrock. 1999. "Generational accounts for the United States: an update." In Generational Accounting Around the World, edited by Alan Auerbach, Laurence Kotlikoff, and Willi Leibfritz. The University of Chicago Press.

Goldin, Claudia and Lawrence Katz. 1999. "The return to skill in the 20th century." Harvard university.

Gordon, Robert. 2002. "Two centuries of economic growth: Europe chasing the American frontier." Paper prepared for the AEA congress (Atlanta). 
Heckman, James, Lance Lochner, and Christopher Taber. 1998. “Explaining Rising Wage Inequality: Explorations with a Dynamic General Equilibrium Model of Labor Earnings with Heterogeneous Agents." Review of Economic Dynamics 1 (1): 1-58.

Kaufman, Martin, Rodolfo Luzio, and Steven Dunaway. 2001. "Returns to human capital and investment in new technology." Working Paper 133, IMF.

Laffargue, Jean-Pierre. 1990. "Résolution d'un modèle macroéconomique à anticipations rationnelles (Solution of a Macroeconomic Model with Rational Expectations. With English summary.)." Annales d'Economie et de Statistisque 0 (17): 97-119.

Ljunqvist, Lars and Thomas Sargent. 1998. "The European unemployment dilemma." Journal of Political Economy 106 (3): 514-550.

Machin, Stephen and John Van Reenen. 1998. "Technology and Changes in Skill Structure: Evidence from Seven OECD Countries." Quarterly Journal of Economics 113 (4): 1215-1244.

Magnac, Thierry and David Thesmar. 2002. "Analyse ećonomique des politiques éducatives: 1'augmentation de la scolarisation en France de 1982 à 1993." Annales d'Economie et de Statistique 65:1-33.

Marimon, Ramon and Fabrizio Zilibotti. 1999. "Unemployment vs. Mismatch of Talents: Reconsidering Unemployment Benefits." Economic Journal 109 (455): 266291.

Psacharopoulos, George. 1994. "Returns to Investment in Education: A Global Update." World Development 22 (9): 1325-43.

Sims, Christopher. 1990. "Solving the stochastic growth model by backsolving with a particular nonlinear form for the decision rule." Journal of Business and Economic Statistics 8 (1): 45-47.

Storesletten, Kjetil. 2000. "Sustaining Fiscal Policy through Immigration." Journal of Political Economy 102 (2): 300-323.

Wasmer, Etienne. 2001a. "Between-group competition in the labour market and the rising returns to skill: US and France 1964-2000." Working Paper, CEPR No 2798.

. 2001b. "Measuring human capital in the labor market: the supply of experience in 8 OECD countries." European Economic Review 45:861-874. 


\section{A Population data}

Figure 9 depicts the population structure per age. For graphical exposition, we assume an equal sharing of the population per sex and we distinguish 8 age groups (from 15-24 to 85-94). Age pyramids for 1960, 2000 and 2050 are reproduced for both countries. They are normalized by setting the overall size of the 15-24 cohort to unity. On these pyramids, aging obviously appears: the relative magnitude of high age cohorts strongly increases over time. The French cumulative survival probabilities are taken from the INED database and the US profile comes from the Berkeley mortality database.

\section{B Education and participation rate data}

For France, the time invested in education is computed using school attendance measures for the 15-24 population reported in Estrade and Minni (1996). Our corresponding estimation, as depicted in Figure 10 amounts to 21\% in 1960, 28,9\% in 1970, 37,5\% in 1980,51\% in 1990 and 59,8\% in 2000. For the US, we use the data and projections on educational attainment by Cheeseman Day and Bauman (2000). Giving the skill structure of the 25-34 population between 1950 and 2000, we compute the time investment in education of successive cohorts. This gives $24,7 \%$ in $1940,31,8 \%$ in $1950,40,5 \%$ in $1960,52,2 \%$ in 1970, 52,1\% in 1980 and 59,1\% in 1990.

The old age participation rate $\alpha$ is computed using the effective retirement age data from Blondal and Scarpetta (1997). Figure 11 presents the data for women and men. We use the average of the two.

\section{Public finance data}

Three proportional taxes are introduced in our model, the labor income tax, the capital income tax and indirect taxes. For France, the indirect tax rate and the rate of tax on capital income are estimated by Carey and Tchilinguirian (2000) at $18 \%$ and $24 \%$ respectively for 1995 . The labor income tax rate is endogenous in the model but needs

a target value: it has been estimated by Eurostat (1999) at 44\% in 1995. For the US, we 
calibrate these tax rates in such a way that the shares of revenues in GDP correspond to the estimations of Gokhale, Page, and Sturrock (1999), i.e. 8\% for labor income, 7\% for indirect taxes and 5\% for capital income in 2000.

In our simulations, we consider (i) that the French tax rate on consumption expenditures increases linearly from 10\% in 1940 to $18 \%$ in 1990 and (ii) that the tax rate on capital income increases from $15 \%$ to $24 \%$ over the same period. The same evolution is applied to the US tax rates (from $8 \%$ to $14 \%$ for the indirect tax rate and from $10 \%$ to $28 \%$ for the capital income tax rate).

We distinguish two types of government spending (net of debt charges), i.e. non age-specific public consumption and age-specific transfers. For the composition of these categories, we build on Crettez, Feist, and Raffelüschen (1999)) for France and Gokhale, Page, and Sturrock (1999) for the US. The history of non age-specific spending is based on OECD data for the period 1960-1995. We assume a constant share in GDP for future years, i.e. 11\% for France (excluding education) and 14\% for the US (including non tertiary education). For age-specific transfers, we use age profiles computed for generational accounting exercises. The French profile is taken from Crettez, Feist, and Raffelüschen (1999) and includes welfare benefits such as pensions, housing, RMI program, child and youth support, health care, education and other transfers. The US profile is taken from Gokhale, Page, and Sturrock (1999) and includes OASDI, medicare and medicaid, tertiary education and other transfers. We incorporate a negative term capturing some taxes (of relatively small amount) which are not explicitly modelled such as the property tax or seigniorage revenue. These age-specific transfers are increasing with age. They are usually more important in France than in the US, especially for individuals aged 55 and more.

Social security benefits and other individual transfers evolve exogenously. Between 1960 and 2000, their level are re-scaled proportionally so as to reproduce the time path of public transfer and pension shares in GDP (as reported by OECD). For future decades, these transfers are adjusted so as to keep the share in GDP constant.

Between 1900 and 2000, the public debt/GDP ratio is exogenously set to its observed value. Observations are taken from OECD statistics for the period 1985-2000. For previous periods, we use data from the French Treasury Department for France and from Brown (1990) for the US. For future decades, we assume that the debt ratio is constant. 
Figure 9: Population by age

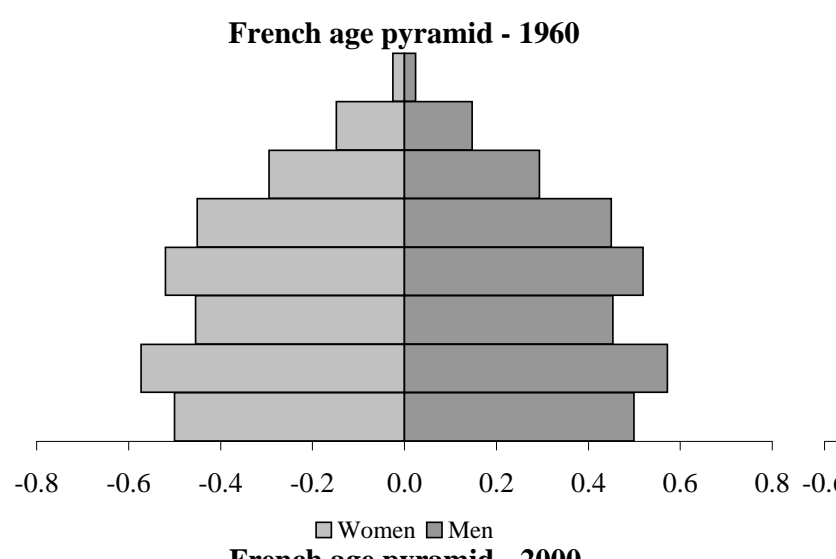

French age pyramid - 2000

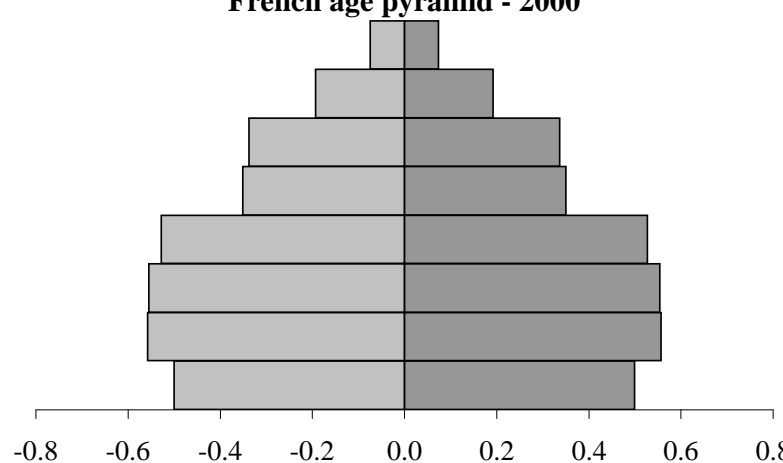

$\square$ Women $\square$ Men

French age pyramid - 2050

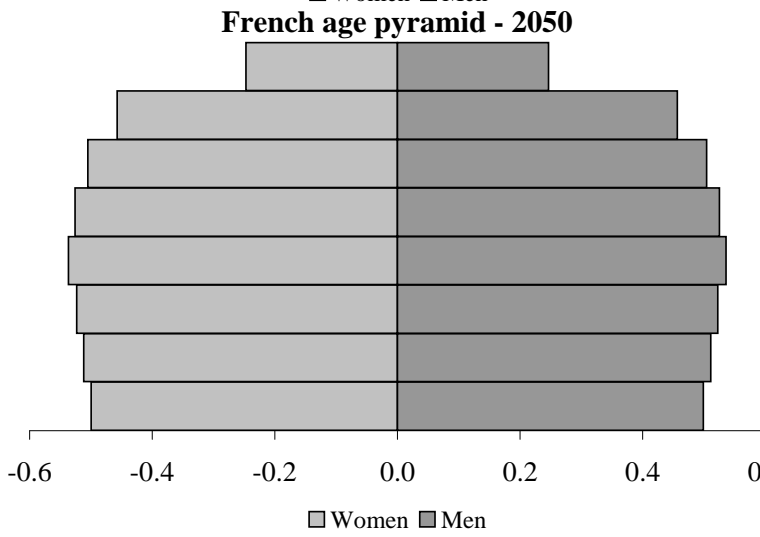

US age pyramid - 1960

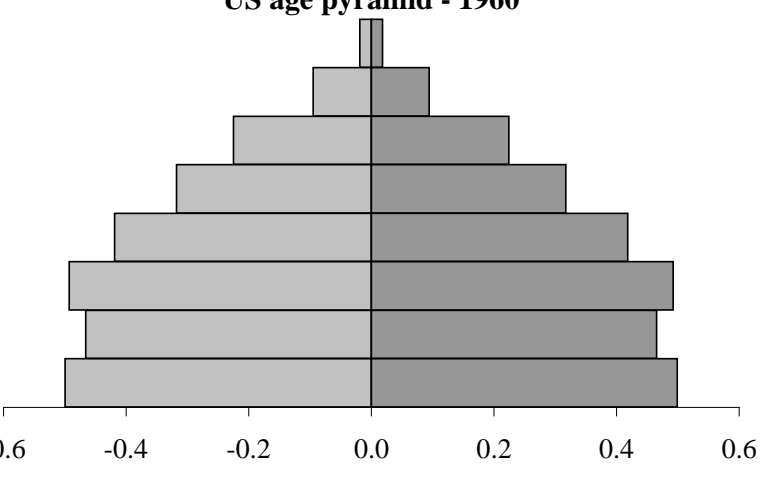

$\square$ Women $\square$ Men

US age pyramid - 2000

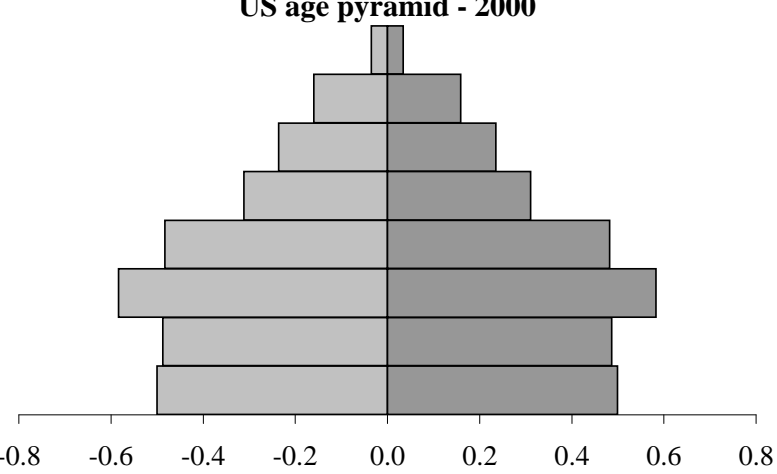

$\square$ Women $\square$ Men

US age pyramid - 2050

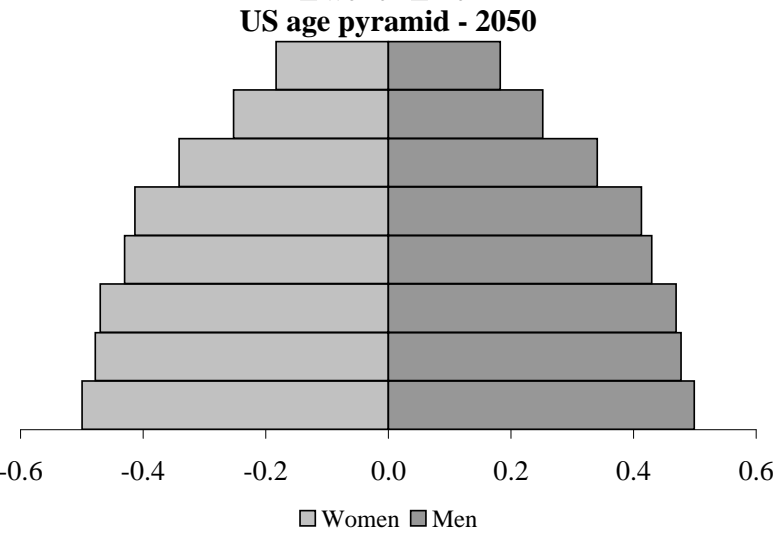


Figure 10: Education investment in France and the US
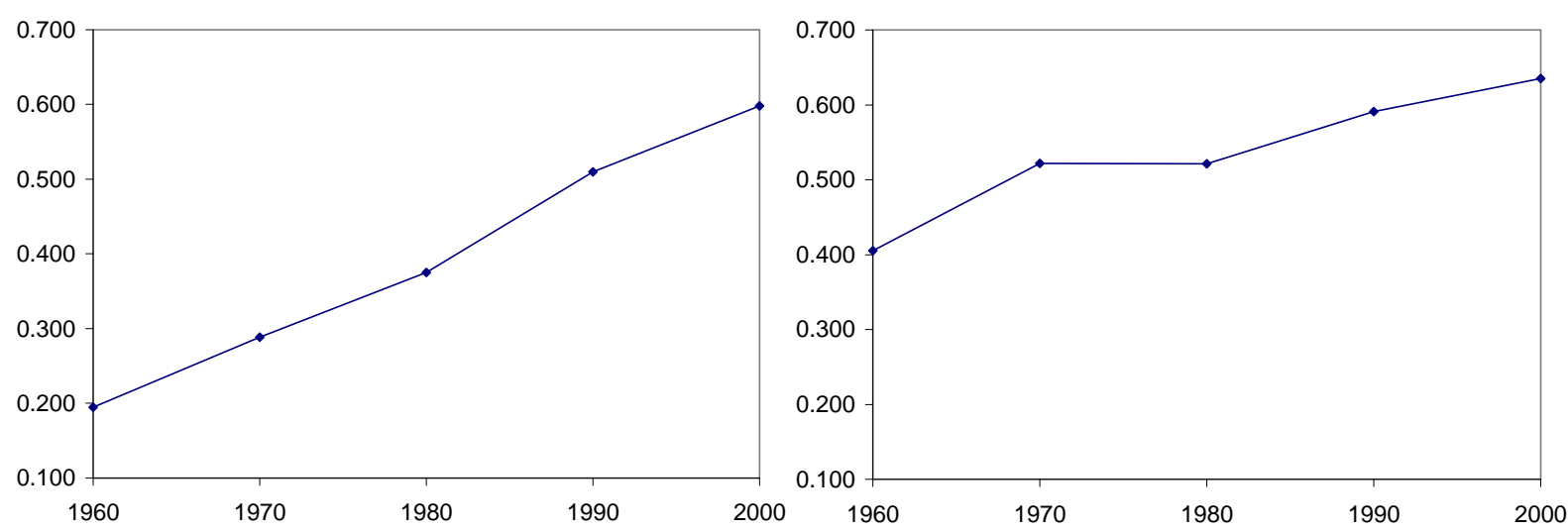

Note: education investment is measured by the percentage of time devoted to education between the age 15 and 25 .

Figure 11: Effective retirement age in France and the US
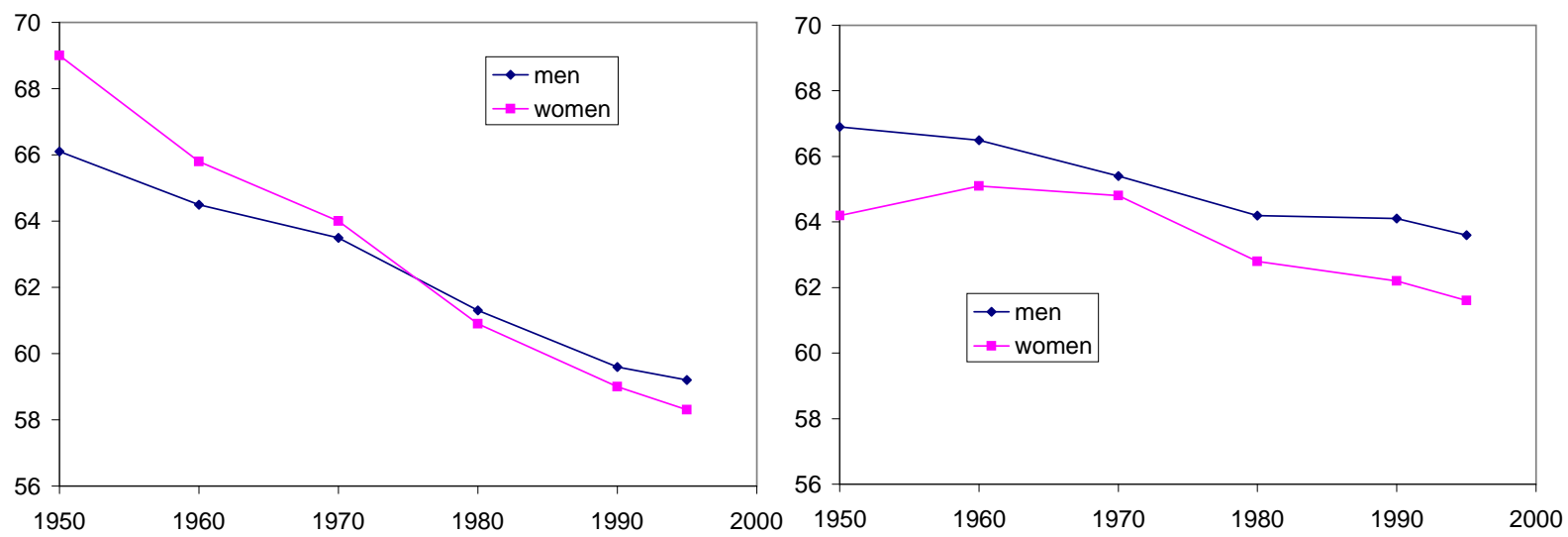